\title{
Stress ocupacional e alteração do Estatuto da Carreira Docente português
}

\author{
A. Rui Gomes \\ Universidade do Minho \\ Ana Peixoto \\ Escola Secundária de Caldas das Taipas \\ Rute Pacheco \\ Maria Silva \\ Universidade do Minho
}

\section{Resumo}

Este estudo foi realizado com 1.162 professores e teve como objetivo analisar a experiência de stress e a síndrome de burnout antes e após a alteração do Estatuto da Carreira Docente em Portugal. Assim, foram efetuadas duas avaliações em momentos temporais distintos, assumindo-se um plano transversal de recolha de dados (2004/2005, $n=689 ; 2008 / 2009, n=473)$. 0 protocolo de avaliação incluiu medidas de fontes de stress e de burnout. Os resultados indicaram que a experiência de stress e de burnout aumentou entre as duas avaliações. Foram encontrados, em 2008/2009, níveis mais altos em áreas relacionadas com pressões de tempo, excesso de trabalho e trabalho burocrático e administrativo; inversamente, houve diminuições em áreas relacionadas com as diferentes capacidades e motivações dos alunos. Quanto à predição da síndrome de burnout, não se verificaram alterações substanciais nas variáveis preditoras nos dois momentos. Em síntese, os resultados indicaram aumentos nas exigências profissionais dos professores, mas não se pode afırmar que tal se deva às alterações do Estatuto da Carreira Docente, uma vez que não observámos alterações no stress associado à carreira docente.

\section{Palavras-chave}

Stress - Burnout - Professores - Estatuto da Carreira Docente. 


\title{
Occupational stress and the change to the Portuguese Statute of the Teaching Career
}

\author{
A. Rui Gomes \\ University of Minho \\ Ana Peixoto \\ Caldas das Taipas Secondary School \\ Rute Pacheco \\ Maria Silva \\ University of Minho
}

\begin{abstract}
This study was carried out with 1162 teachers with the objective of analyzing their experiences of stress and burnout syndrome before and after the change to the Portuguese Statute of the Teaching Career. Two assessments were made at different moments, with the adoption of a transversal plan of data gathering (2004/2005, $n=689 ; 2008 / 2009, n=473)$. The assessment protocol included measurements of the sources of stress and burnout. Results indicate that the experiences of stress and burnout increased between the two assessments. In 2008/2009 stress and burnout levels were higher in areas related to time pressure, excessive work, and bureaucratic and administrative work; inversely, there were reductions in areas related to the different capacities and motivations of the pupils. As to the prediction of burnout syndrome, there were no substantial changes in the predicting variables between the two moments. In synthesis, results indicate increases in the professional demands made of teachers, but it cannot be affirmed that these are due to the changes in the Statute of the Teaching Career, since no changes were observed in the stress associated to the teaching career.
\end{abstract}

\section{Keywords}

Stress - Burnout - Teachers - Statute of the Teaching Career.

Contact:

Rui Gomes

Universidade do Minho

Escola de Psicologia

Campus de Gualtar

4710-057 - Braga, Portugal

rgomes@psi.uminho.pt 
Ser professor significa optar por uma das profissões mais exigentes em termos da exposição ao stress ocupacional (ARONSSON; SVENSSON; GUSTAFSSON, 2003; BROTHERIDGE; GRANDEY, 2002; JOHNSON et al., 2005; SANN, 2003). As razões que explicam essa situação são várias, nomeadamente, o relacionamento com os alunos (PITHERS, 1995; TURK; MEEKS; TURK, 1982), o salário inadequado e a percepção de baixo estatuto profissional (CARLSON; THOMPSON, 1995), os conflitos e a ambiguidade de papéis (DUNHAM, 1992), as pressões de tempo (CHAN, 1998), a relação com os supervisores (LITT; TURK, 1985) e mesmo o ter de lecionar a turmas com maior número de alunos do que o aconselhável (BURKE; GREENGLASS, 1994).

Dentre esses fatores de stress, alguns derivam de mudanças no funcionamento organizacional, existindo autores que defendem a possibilidade de o stress organizacional poder ter consequências significativas na atividade docente, principalmente no nível físico (e.g., fadiga, insónias, dores de cabeça e tensão nervosa) e psicológico (ansiedade, depressão, exaustão emocional e mesmo burnout) (KYRIACOU; PRATT, 1985; PIERCE; MOLLOY, 1990; PITHERS; SODEN, 1999). Tal aspeto é tão mais importante pois essas dificuldades físicas e psicológicas podem, por sua vez, levar a outros problemas, como o decréscimo do rendimento profissional, a menor satisfação profissional, a diminuição da autoestima, a má tomada de decisão e a ocorrência de julgamentos errados (DINHAM, 1993; HOWARD; JOHNSON, 2004). Assim sendo, alguns autores têm vindo a chamar a atenção para a necessidade de compreendermos o conjunto de forças mais alargadas, nos âmbitos social, cultural e económico, que podem originar pressões sobre o funcionamento das organizações e dos indivíduos que lá trabalham (MASLACH; SCHAUFELI; LEITER, 2001). Do nosso ponto de vista, podem também aqui ser incluídas as mudanças que decorrem das políticas governamentais, que depois se traduzem em alterações no funcionamento de cada organização em causa. Dito por outras palavras, a modificação das normas legais definidas ao nível político pode representar uma fonte de tensão para as organizações, repercutindo-se, em última estância, em cada um dos profissionais.

É nesse sentido que este trabalho pode ser enquadrado, procurando estudar a experiência profissional de professores do ensino básico e secundário portugueses em resultado das alterações do Estatuto da Carreira Docente introduzidas em 2007 e 2009 pelo Governo Português, por meio do Ministério da Educação. Mais concretamente, em 2007, foram propostas mudanças significativas na carreira docente dos professores do ensino básico e secundário, de onde se pode destacar a alteração das categorias profissionais (passando a existir as categorias de professor e professor titular), bem como as transformações no regime de avaliação de desempenho, definido como mais exigente e com efeitos no desenvolvimento da carreira (ver Decreto-Lei $\mathrm{n}^{\circ} 15$, PORTUGAL, 2007). Uma das mudanças mais signifıcativas na avaliação dos professores prendeu-se com o facto de esta passar a ser da responsabilidade principal de figuras externas a cada professor avaliado, intervindo nesse processo os coordenadores dos departamentos curriculares ou dos conselhos de docentes, inspetores com formação científica na área do professor avaliado, bem como os órgãos de direção das escolas. 0 resultado dessa avaliação passou a ser expresso em cinco menções qualitativas, sendo defınidas duas classificações superiores a que nem todos os professores podem aceder (regime de quotas) e que dão direito a um prémio de desempenho.

Esse conjunto de propostas foi objeto de significativa contestação social por parte dos professores, originando diversas manifestações públicas contra o novo estatuto de carreira. A título de exemplo, em março de 2008 ocorreu a maior manifestação de 
professores em Portugal, a qual terá juntado mais de 100 mil docentes reivindicando alterações no estatuto da carreira e a demissão da então Ministra da Educação (ver LIMA, 2008). Na sequência desses acontecimentos, em 2009, o Ministério da Educação publicou algumas variações ao Decreto-Lei no 15/2007, prevendo mudanças nos tempos de permanência nos escalões de carreira, a criação de novos escalões, a alteração dos tempos de serviço para o recrutamento de professores titulares, entre outras (ver Decreto-Lei no 270, PORTUGAL, 2009). Mais recentemente, em 2010, o Decreto-Lei ${ }^{\circ} 75$ vem propor que a carreira docente seja constituída apenas pela categoria de professor. Curiosamente, hoje em dia, continuam a decorrer negociações entre o governo e os representantes sindicais dos professores tendo em vista resolver alguns dos problemas ainda presentes (por exemplo, a existência de regime de quotas na classificação dos professores, a simplificação do regime de avaliação, a existência de ciclos de avaliação mais longos no tempo etc.) (ver MOLEIRO, 2011).

Seja como for, no conjunto dessa revisão do Estatuto da Carreira Docente, ocorreram transformações significativas na atividade dos professores e no modo como estes passaram a perspectivar suas carreiras, transformações estas que importa agora estudar. Para tal, este trabalho incluiu dois períodos temporais de recolha de dados, que ocorreram nos anos letivos de 2004/2005 e 2008/2009. As razões da escolha desses dois anos letivos devem-se ao facto de os professores viverem realidades distintas em termos de seu Estatuto de Carreira Docente. Ou seja, em 2004/2005, não tinha sido publicada qualquer alteração legal, e, em 2008/2009, os professores estavam já confrontados com o novo regime legal.

Assim sendo, este estudo procurou verificar se a experiência de stress e da síndrome de burnout dos professores modificou-se entre o período anterior às mudanças legais
(2004/2005) e o período subsequente a essas mesmas mudanças (2008/2009).

No entanto, convém esclarecer alguns aspetos prévios à realização deste estudo. Em primeiro lugar, o planejamento da investigação não foi pensado desde o início para avaliar tais alterações no Estatuto da Carreira Docente. Na realidade, o estudo de 2004/2005 não foi implementado para esse efeito, destinando-se, antes, a avaliar a experiência geral de stress ocupacional no ensino (ver GOMES et al., 2010). Entretanto, dadas todas as mudanças referidas e as significativas manifestações sociais e profissionais de mal-estar por parte dos professores após a introdução do Decreto-Lei $\mathrm{n}^{\circ} 15$, de 2007, tornou-se interessante analisar os efeitos na experiência profissional dos professores, e, por isso, realizou-se a recolha de dados de 2008/2009. Mas, uma vez que o primeiro estudo de 2004/2005 não tinha - nem podia ter - sido pensado para esse efeito comparativo, não nos foi possível desenvolver uma metodologia de medidas repetidas com amostras emparelhadas, incluindo na amostra os mesmos professores em ambos os momentos de recolha de dados. Por isso, deve ser salvaguardado que este estudo incluiu duas amostras independentes, que têm como denominador central respeitarem a momentos temporais em que a realidade de funcionamento dos professores foi significativamente alterada.

Quanto às medidas psicológicas aplicadas, foram utilizados dois instrumentos iguais nos dois momentos temporais, o que permitiu um confronto exato da eventual alteração da experiência profissional (e.g., fontes de stress e síndrome de burnout). A escolha da variável de stress relacionou-se com o tema deste estudo, ou seja, verificar se as dimensões de pressão profissional sofreram flutuações nos períodos temporais assinalados. Quanto ao burnout, o interesse por seu estudo decorreu do facto de a síndrome ser uma das consequências mais problemáticas associadas ao stress ocupacional. Tal problema incorpora sensações de exaustão 
física e emocional, o desenvolvimento de atitudes cínicas ante o ensino e os outros (o que é também conhecido como despersonalização), e a redução do sentimento de realização pessoal no trabalho (MASLACH; JACKSON; LEITER, 1996). 0 resultado desse processo é a diminuição da satisfação profissional, um pior ajustamento pessoal e profissional dos professores e a ocorrência de efeitos negativos sobre os próprios estudantes e sobre o sistema de ensino (BRACKETT et al., 2010; BURKE; GREENGLASS; SCHWARZER, 1996; CARLOTTO, 2002; GREENGLASS, FIKSENBAUM; BURKE, 1996; VANDENBERGHE; HUBERMAN, 1999; WESTMAN, 2001). Nesse sentido, este estudo incluiu uma medida de burnout que avaliou as dimensões exaustão emocional, despersonalização e realização pessoal (MASLACH; SCHAUFELI; LEITER, 2001).

Assim sendo, o trabalho pretendeu atingir os seguintes objectivos:

i) analisar os níveis globais de stress, os fatores de stress e os níveis de burnout nos dois períodos de avaliação (2004/2005 e 2008/2009);

ii) analisar as diferenças na experiência de stress e sindrome de burnout nos dois períodos de avaliação (2004/2005 e 2008/2009);

iii) observar as variáveis de stress preditoras da sindrome de burnout nos dois períodos de avaliação (2004/2005 e 2008/2009).

\section{Método}

\section{Participantes}

A amostra foi constituída por dois conjuntos de professores que lecionavam nos anos letivos de 2004/2005 e 2008/2009. A recolha da amostra procurou seguir alguma uniformidade em termos de zona geográfica e realidade educativa dos professores. Assim, estabelecemos como prioridade incluirmos na amostra professores de zonas urbanas dos distritos de Braga e Porto (zona norte de Portugal). Tal critério foi evidente na amostra de 2004/2005, mas o mesmo não foi possível na amostra de 2008/2009, devido a dificuldades no processo de recolha de dados. Por isso, nesse último caso, optámos por complementar a amostra com professores da Região Autónoma dos Açores, que constituiu parte significativa do grupo de participantes no segundo momento de recolha de dados. Assim, de modo a controlarmos essa disparidade na constituição da amostra, procuramos certificar-nos de que as eventuais diferenças nas variáveis analisadas mantinham-se quando retirados da amostra os professores da Região Autónoma dos Açores. Como veremos mais à frente, esse cuidado foi particularmente relevante quando efetuámos análises comparativas entre as duas amostras.

No total, este estudo inclui 1.162 professores. Mais concretamente, no ano letivo de 2004/2005, foram incluídos 689 professores da zona norte de Portugal, a lecionarem nos ciclos básico $(n=272,39,5 \%)$ e secundário $(n=417,60,5 \%)$, sendo 482 do sexo feminino (70\%) e 207 do sexo masculino (30\%), com idades compreendidas entre os 22 e os 65 anos $(M=41,10 ; D P=9,35)$. No ano letivo de 2008/2009, foram incluídos 473 professores que exerciam sua atividade na zona norte de Portugal $(n=193,40,8 \%)$ e na Região Autónoma dos Açores ( $n=280,59,2 \%)$. Nesse caso, os professores lecionavam nos ciclos básico $(n=343,72,5 \%)$ e secundário ( $n=130$, $27,5 \%)$, sendo 321 do sexo feminino $(67,9 \%)$ e 152 do sexo masculino (32,1\%), tendo idades compreendidas entre os 23 e os 61 anos $(M=39,38 ; D P=8,97)$.

\section{Medidas}

Foi administrado a todos os docentes um conjunto de instrumentos destinados a obter informações acerca das variáveis em análise neste estudo.

- Questionário de Stress nos Professores (QSP, GOMES et al., 2006): 0 instrumento é constituído por duas partes distintas, sendo a primeira caracterizada por uma questão des- 
tinada a avaliar o nível global de stress dos professores, numa escala que varia entre zero (nenhum stress) e quatro (muito stress). $\mathrm{Na}$ segunda parte, foram incluídos 36 itens correspondentes a diferentes fontes de stress no processo de ensino, distribuindo-se por seis dimensões: i) comportamentos inadequados e indisciplina dos alunos: avalia os problemas de comportamento dos alunos e as dificuldades dos professores em gerir a indisciplina na sala de aula (e.g., "mau comportamento contínuo de alguns alunos") (valores de Alpha de 0,94 em 2004/2005, e de 0,93 em 2008/2009); ii) pressões de tempo e excesso de trabalho: avalia as dificuldades de tempo sentidas pelos professores para prepararem adequadamente as aulas e cumprirem os planos curriculares, bem como os problemas associados ao excesso de trabalho decorrente de suas obrigações profissionais (e.g., "demasiado trabalho para fazer") (valores de Alpha de 0,84 em ambos os momentos letivos); iii) diferentes capacidades e motivações dos alunos: avalia as contrariedades sentidas pelos professores no ensino de alunos com níveis de aprendizagem distintos e as dificuldades em estabelecerem objetivos específicos para cada um deles (e.g., "alunos com baixas capacidades") (valores de Alpha de 0,86 em 2004/2005, e de 0,88 em 2008/2009); iv) carreira docente: avalia os sentimentos negativos dos professores relativamente a vários aspetos de sua carreira profissional (e.g., "baixo estatuto socioprofissional da profissão") (valores de Alpha de 0,88 em 2004/2005, e de 0,88 em 2008/2009); v) trabalho burocrático e administrativo: avalia as reações desfavoráveis dos professores dirigidas às obrigações burocráticas e de carácter administrativo inerentes à sua atividade profissional (e.g., "o trabalho administrativo") (valores de Alpha de 0,95 em 2004/2005, e de 0,94 em 2008/2009); e, por último, vi) políticas disciplinares inadequadas: avalia as dificuldades sentidas pelos professores relativamente às políticas disciplinares ao seu dispor, bem como a pouca aceitação de sua autorida- de e de seu poder (e.g., "sanções disciplinares pouco adequadas") (valores de Alpha de 0,89 em 2004/2005, e de 0,86 em 2008/2009). Os itens foram respondidos numa escala tipo Likert de cinco pontos $(0=$ nenhum stress; 4 = muito stress), podendo os resultados em cada um dos fatores variarem entre um mínimo de zero e um máximo de quatro, representando os valores máximos níveis mais elevados de stress.

- Inventário de Burnout de Maslach Versão para Professores (IBM-VP, MASLACH; JACKSON; SCHWAB, 1996; adaptação de GOMES et al., 2006): O IBM-VP é um instrumento de autorregisto com 22 itens acerca dos sentimentos relacionados com o trabalho, avaliando três dimensões distintas: i) exaustão emocional: avalia os sentimentos de sobrecarga emocional e exaustão devido às exigências do trabalho (e.g., "sinto-me esgotado(a) com o meu trabalho") (valores de Alpha de 0,89 em 2004/2005, e de 0,91 em 2008/2009); ii) despersonalização: avalia as respostas frias, impessoais ou mesmo negativas dirigidas àqueles a quem se prestam serviços (e.g., "sinto que trato alguns alunos como se fossem objetos impessoais") (valores de Alpha de 0,65 em 2004/2005, e de 0,70 em 2008/2009); e iii) realização pessoal: avalia os sentimentos de competência profissional e de sucesso no trabalho com pessoas (e.g., "neste emprego consegui muitas coisas que valeram a pena") (valores de Alpha de 0,74 em 2004/2005, e de 0,79 em 2008/2009). Os itens variam numa escala tipo Likert de sete pontos, entre um mínimo de zero (nunca) e um máximo de seis (todos os dias). Assim sendo, o perfil pleno de síndrome de burnout verifica-se quando temos elevados scores de exaustão emocional e despersonalização e, inversamente, baixos scores de realização pessoal.

\section{Procedimento}

Ambas as recolhas de dados seguiram os mesmos procedimentos de execução e 
tratamento dos dados. Assim, começámos por efetuar um pedido para a realização de ambos os estudos aos responsáveis dos conselhos executivos ou diretivos das instituições de ensino, explicando os objetivos do estudo e os procedimentos a levar a cabo na recolha, no tratamento e na divulgação dos dados. Após a anuência em participar, efetuámos os estudos de campo.

0 questionário, que englobava os instrumentos aqui referidos, foi distribuído por meio de recolha direta, com uma carta de apresentação dirigida aos participantes acerca dos objetivos e implicações da investigação, e assegurando o carácter voluntário de sua participação. Apenas os participantes que concordaram com as condições de realização do estudo foram incluídos na amostra final. No sentido de garantir a confidencialidade e o anonimato dos dados recolhidos, foi fornecido a todos os inquiridos um envelope no qual introduziam o questionário preenchido. A abertura dos envelopes contendo os questionários recebidos foi sempre da única e exclusiva responsabilidade do grupo de investigadores responsáveis pelo estudo, de forma a garantir a confidencialidade dos dados.

Assim sendo, no ano letivo de 2004/2005 obtivemos uma taxa de retorno e adesão de 65,6\%, ao passo que em 2008/2009 alcançámos uma taxa de retorno e adesão de 59,9\%.

\section{Resultados}

0 tratamento e a análise estatística dos dados foram efetuados no programa SPSS (versão 18.0 para Windows) e incluíram vários procedimentos que serão explicados ao longo desta parte do trabalho.

\section{Níveis de stress e de burnout}

Começando pelo nivel global de stress que os docentes sentem geralmente no exer- cício de sua atividade profissional (primeira parte do QSP), o principal aspeto a realçar é o facto de assistirmos a um aumento dos níveis mais elevados de stress. Assim, se somarmos os valores relativos a bastante e elevado stress, verificamos que, em 2004/2005, estes eram de $38 \%$, e que subiram para 50\% dos participantes no estudo em 2008/2009.

No que se refere aos fatores de stress do QSP, três ideias devem ser referidas. Desde logo, os problemas relacionados com os comportamentos inadequados e de indisciplina dos alunos mantêm-se como o principal domínio gerador de mal-estar nos professores. No entanto, no segundo fator de stress, verificou-se uma alteração do ranking das dimensões avaliadas, sendo que, em 2004/2005, foram as políticas disciplinares inadequadas a perturbar os professores, enquanto, em 2008/2009, surge o trabalho burocrático e administrativo como segundo domínio gerador de mal-estar. É curioso assinalar, ainda, que as diferentes capacidades e motivações dos alunos eram o terceiro fator de stress em 2004/2005, passando para último lugar em 2008/2009, e que as preocupações com a carreira docente eram a última fonte de stress em 2004/2005, subindo para quinto lugar em 2008/2009.

Quanto à síndrome de burnout, em nenhum dos momentos de avaliação observámos casos de burnout pleno, mas é de registar que todas as dimensões aumentaram de percentagem de frequência de 2004/2005 para 2008/2009, continuando a ser a exaustão emocional a faceta mais prevalente, seguida pela baixa realização pessoal e, por último, pela despersonalização. É importante referir que esses cálculos foram efetuados tendo por base as indicações sugeridas por Arie Shirom (1989) e as adaptações subsequentes propostas por Gomes e colaboradores (2010).

Todos esses valores podem ser consultados na Tabela 1. 
Tabela 1 - Valores de stress e de burnout nos dois momentos de recolha de dados

\begin{tabular}{|c|c|c|}
\hline & $2004 / 2005$ & $2008 / 2009$ \\
\hline QSP: Nível global de stress & $n(\%)$ & $n(\%)$ \\
\hline Nenhum stress & $5(1,7)$ & $5(1,5)$ \\
\hline Pouco stress & $50(16,9)$ & $32(9,8)$ \\
\hline Moderado stress & $130(43,9)$ & $126(38,5)$ \\
\hline Bastante stress & $88(29,7)$ & $132(40,4)$ \\
\hline \multirow[t]{2}{*}{ Elevado stress } & $23(7,8)$ & $32(9,8)$ \\
\hline & $2004 / 2005$ & $2008 / 2009$ \\
\hline QSP: Fatores de stress & M(DP) Ranking & $M(D P)$ Rankin \\
\hline Comportamentos inadequados e indisciplina dos alunos & $2,81(0,89) \quad 1$ & $2,89(0,91)$ \\
\hline Pressões de tempo e excesso de trabalho & $2,41(0,82) \quad 5$ & $2,51(0,82)$ \\
\hline Diferentes capacidades e motivações dos alunos & $2,49(0,79) \quad 3$ & $2,09(0,95)$ \\
\hline Carreira docente & $2,38(0,89) \quad 6$ & $2,32(0,93)$ \\
\hline Trabalho burocrático e administrativo & $2,42(0,98) \quad 4$ & $2,76(0,96)$ \\
\hline Políticas disciplinares inadequadas & $2,55(0,86) \quad 2$ & $2,59(0,94)$ \\
\hline MBI: Níveis de burnout & $n(\%)$ & $n(\%)$ \\
\hline Exaustão emocional & $75(10)$ & $98(18)$ \\
\hline Despersonalização & $4(0,4)$ & $14(2,3)$ \\
\hline Baixa realização pessoal & $19(2,8)$ & $17(3,4)$ \\
\hline
\end{tabular}

Fonte: Dados da pesquisa.

\section{Diferenças na experiência de stress e de burnout}

0 objetivo desta análise foi verificar a existência de diferenças na experiência de stress e de burnout nos dois momentos de recolha de dados. Ao efetuarmos as análises, tivemos em atenção os pressupostos de aplicação dos testes paramétricos. De um modo geral, não se assistiram a problemas de normalidade nesta análise e, nos casos em que tal ocorreu, testámos as diferenças utilizando os testes paramétricos e não paramétricos correspondentes, seguindo, assim, as indicações de Fife-Schaw (2006). Dado que os resultados, em geral, foram similares, optámos por usar os testes paramétricos, uma vez que são mais robustos e possibilitam o uso de análises multivariadas. Além disso, tais análises têm como vantagem adicional a redução do número de testes a executar, diminuindo, assim, a probabilidade do erro Tipo 1 .
Começando pelas diferenças no nível global de stress, observou-se um aumento significativo nessa dimensão da avaliação de 2004/2005 para 2008/2009.

No que se refere aos fatores de stress, foram encontradas diferenças significativas nas dimensões avaliadas (Wilks' $\lambda=0,86, F(6$, $\left.1150)=32,55, p<0,001, \eta^{2}=0,15\right)$. Os testes univariados demonstraram que a percepção de stress aumentou em 2008/2009 relativamente a 2004/2005 nas facetas de comportamentos inadequados e indisciplina dos alunos (mas aqui os valores foram quase significativos a $p<0,10$ com o teste paramétrico, e significativos com o teste não paramétrico correspondente), nas pressões de tempo e excesso de trabalho (nesse caso, as diferenças foram quase significativas com a aplicação do teste não paramétrico correspondente), nas diferentes capacidades e motivações dos alunos, e no trabalho burocrático e administrativo. É importante referir que todas essas diferenças 
mantiveram-se quando retiramos da comparação os professores da Região Autónoma dos Açores.

De igual modo, foram encontradas diferenças significativas nas dimensões da síndrome de burnout (Wilks' $\lambda=0,96, F(3,1153)$ $\left.=18,03, p<0,001, \eta^{2}=0,05\right)$. Os testes univariados apontaram igualmente que, relativamente a 2004/2005, em 2008/2009 os professores evidenciaram maior exaustão emocional, despersonalização e, inversamente, menor realização pessoal. No entanto, se excluirmos da amostra de 2008/2009 os professores da Região Autónoma dos Açores, essas diferenças só são significativas na dimensão de exaustão emocional, tendo-se igualmente verificado valores de Wilks significativos (Wilks' $\lambda=0,98$, $\left.F(3,874)=4,77, p<0,01, \eta^{2}=0,02\right)$.

Todos esses valores podem ser consultados na Tabela 2.

Tabela 2 - Diferenças nas variáveis de stress e burnout nos dois momentos de recolha de dados

\begin{tabular}{|c|c|c|c|c|c|c|}
\hline VARIÁVEL & $\frac{2004 / 2 C}{M(D P)}$ & & $\frac{2008 / 2 C}{M(D P)}$ & $\frac{09}{(n)}$ & $\begin{array}{c}t \\
(621) \\
\end{array}$ & $\begin{array}{c}F \\
(1,1155)\end{array}$ \\
\hline \multicolumn{7}{|l|}{ QSP: Fatores de stress } \\
\hline Nível global de stress & $2,25(0,89)$ & (296) & $2,47(0,86)$ & (327) & $-3,16^{\star *}$ & -- \\
\hline Comportamentos inadequados e indisciplina dos alunos & $2,81(0,89)$ & (685) & $2,90(0,91)$ & $(472)$ & -- & $2,75^{+}$ \\
\hline Pressões de tempo e excesso de trabalho & $2,41(0,82)$ & (685) & $2,51(0,83)$ & $(472)$ & -- & $4,05^{*}$ \\
\hline Diferentes capacidades e motivações dos alunos & $2,48(0,78)$ & (685) & $2,09(0,95)$ & $(472)$ & -- & $58,49^{\star \star \star}$ \\
\hline Carreira docente & $2,38(0,89)$ & (685) & $2,31(0,93)$ & $(472)$ & -- & n.s. \\
\hline Trabalho burocrático e administrativo & $2,42(0,98)$ & (685) & $2,76(0,97)$ & $(472)$ & -- & $34,27^{\star \star \star}$ \\
\hline Políticas disciplinares inadequadas & $2,55(0,86)$ & (685) & $2,59(0,94)$ & $(472)$ & -- & n.s. \\
\hline \multicolumn{7}{|l|}{ MBI: Fatores de burnout } \\
\hline Exaustão emocional & $2,04(1,29)$ & (685) & $2,62(1,42)$ & $(472)$ & -- & $51,39^{\star \star \star}$ \\
\hline Despersonalização & $0,76(0,85)$ & (685) & $1,04(1,09)$ & $(472)$ & -- & $23,74^{\star \star \star}$ \\
\hline Realização pessoal & $4,16(10,02)$ & (685) & $4,02(1,01)$ & $(472)$ & -- & $5,44^{*}$ \\
\hline
\end{tabular}

n.S. = não significativo; $\quad{ }^{+} p<0,10 ; \quad{ }^{*} p<0,05 ; \quad{ }^{* \star} p<0,01 ; \quad{ }^{* \star \star} p<0,001$

Fonte: Dados da pesquisa.

\section{Variáveis preditoras da experiência de burnout}

0 objectivo aqui foi compreender quais fatores de stress melhor poderiam explicar a síndrome de burnout em suas três dimensões, tendo a análise sido realizada separadamente para os dois períodos de estudo em causa. Nesse sentido, efetuámos análises de regressão múltipla, através do método enter.

Começando pelo ano letivo de 2004/2005, foi possível verifıcar que a dimensão de exaustão emocional foi a variável com maior percentagem de variância explicada (27\%), seguida pela realização pessoal (3\%) e pela despersonalização (2\%) (ver Tabela 3). No caso da exaustão emocional, esta foi predita por maiores níveis de stress associados aos comportamentos inadequados e de indisciplina dos alunos, às pressões de tempo e excesso de trabalho e às diferentes capacidades e motivações dos alunos. Já a tendência para a despersonalização foi predita pelos comportamentos inadequados e de indisciplina dos alunos. Por fim, a baixa realização pessoal foi predita pelo maior stress relacionado com os comportamentos inadequados e de indisciplina dos alunos.

Para o ano letivo de 2008/2009, constatou-se um padrão semelhante de variância explicada, sendo novamente a exaustão emocional a faceta mais bem predita (35\%), seguida pela realização pessoal (10\%) e só depois pela desper- 
sonalização (4\%) (ver Tabela 4). Assim, no caso da exaustão emocional, esta foi também predita pelo stress associado aos comportamentos inadequados e de indisciplina dos alunos, às pressões de tempo e excesso de trabalho e às diferentes capacidades e motivações dos alunos. A tendência para a despersonalização foi predita pelas diferentes capacidades e motivações dos alunos. Finalmente, a baixa realização pessoal foi predita por um conjunto de três fatores de stress, nomeadamente, as diferentes capacidades e motivações dos alunos, o trabalho burocrático e administrativo (embora o sentido da predição seja positivo) e as políticas disciplinares inadequadas.

Tabela 3 - Modelos de regressão para a predição da síndrome de burnout em 2004/2005

\begin{tabular}{|c|c|c|c|c|}
\hline Predição da exaustão emocional & & & & \\
\hline & $\mathrm{R}^{2}$ ( $\mathrm{R}^{2}$ ajust.) & $F(6,675)$ & $\beta$ & $t$ \\
\hline QSP: Fatores de stress & \multirow{4}{*}{$0,28(0,27)$} & \multirow{4}{*}{$42,65^{\star \star \star}$} & & \\
\hline Comportamentos inadequados e indisciplina dos alunos & & & 0,25 & $5,45^{\star \star \star}$ \\
\hline Pressões de tempo e excesso de trabalho & & & 0,26 & $5,56^{\star \star \star}$ \\
\hline Diferentes capacidades e motivações dos alunos & & & 0,10 & $2,20^{*}$ \\
\hline \multicolumn{5}{|l|}{ Predição da despersonalização } \\
\hline & $\mathrm{R}^{2}$ ( $\mathrm{R}^{2}$ ajust.) & $\boldsymbol{F}(6,436)$ & $\beta$ & $t$ \\
\hline \multicolumn{5}{|l|}{ QSP: Fatores de stress } \\
\hline Comportamentos inadequados e indisciplina dos alunos & $0,04(0,02)$ & $2,61^{*}$ & 0,24 & $3,16^{*}$ \\
\hline \multicolumn{5}{|l|}{ Predição da baixa realização pessoal } \\
\hline & $R^{2}$ ( $R^{2}$ ajust.) & $\boldsymbol{F}(6,671)$ & $\beta$ & $t$ \\
\hline \multicolumn{5}{|l|}{ QSP: Fatores de stress } \\
\hline Comportamentos inadequados e indisciplina dos alunos & $0,04(0,03)$ & $4,51^{\star \star \star}$ & $-0,19$ & $-3,66^{\star \star \star}$ \\
\hline
\end{tabular}

${ }^{*} p<0,05 ; \quad{ }^{* * *} p<0,001$

Fonte: Dados da pesquisa.

Tabela 4 - Modelos de regressão para a predição da síndrome de burnout em 2008/2009

\begin{tabular}{|c|c|c|c|c|}
\hline \multicolumn{5}{|l|}{ Predição da exaustão emocional } \\
\hline & $\mathrm{R}^{2}$ ( $\mathrm{R}^{2}$ ajust.) & $F(6,464)$ & $\beta$ & $t$ \\
\hline QSP: Fatores de stress & & & & \\
\hline Comportamentos inadequados e indisciplina dos alunos & \multirow{3}{*}{$0,35(0,35)$} & \multirow{3}{*}{$42,38^{\star \star \star}$} & 0,14 & $2,34^{*}$ \\
\hline Pressões de tempo e excesso de trabalho & & & 0,32 & $6,09^{\star \star \star}$ \\
\hline Diferentes capacidades e motivações dos alunos & & & 0,22 & $4,49^{\star \star \star}$ \\
\hline \multicolumn{5}{|l|}{ Predição da despersonalização } \\
\hline & $R^{2}$ ( $R^{2}$ ajust.) & $F(6,450)$ & $\beta$ & $t$ \\
\hline QSP: Fatores de stress & & & & \\
\hline Diferentes capacidades e motivações dos alunos & $0,5(0.4)$ & $4,28^{\star \star \star}$ & 0,21 & $3,54^{\star \star \star}$ \\
\hline \multicolumn{5}{|l|}{ Predição da baixa realização pessoal } \\
\hline & $\mathrm{R}^{2}$ ( $\mathrm{R}^{2}$ ajust.) & $F(6,464)$ & $\beta$ & $t$ \\
\hline QSP: Fatores de stress & & & & \\
\hline Diferentes capacidades e motivações dos alunos & & & $-0,19$ & $-3,33^{\star *}$ \\
\hline Trabalho burocrático e administrativo & $0,11(0,10)$ & $9,60^{\star \star *}$ & 0,27 & $4,67^{\star \star \star}$ \\
\hline Políticas disciplinares inadequadas & & & $-0,19$ & $-2,47^{\star}$ \\
\hline
\end{tabular}

${ }^{*} p<0,05 ; \quad{ }^{* *} p<0,01 ; \quad{ }^{* * *} p<0,001$

Fonte: Dados da pesquisa. 
Discussão

0 estudo do stress ocupacional nos professores é um tema fascinante e complexo devido à multiplicidade de fatores que podem perturbar o funcionamento ótimo desses profissionais. Kyriacou (2001), por exemplo, procurou sintetizar os dados de vários estudos realizados sobre o tema e encontrou dez (!) dimensões principais de stress: ensinar estudantes com baixa motivação; manter a disciplina em sala de aula; enfrentar pressões de tempo e excesso de trabalho; lidar com a mudança; ser avaliado pelos outros; relacionar-se com os colegas; sentir-se com baixo estatuto profissional, o que conduz a uma baixa autoestima; ter problemas com a gestão e com decisores administrativos; enfrentar conflito e ambiguidade de papéis; e, por último, estar em más condições de trabalho.

Este estudo centra-se fundamentalmente no impacto que as mudanças no estatuto da carreira docente podem produzir na experiência profissional dos professores, fazendo, assim, a ligação entre as dimensões de stress de lidar com a mudança e o ter de ser avaliado pelos outros, tal como descrito por Kyriacou (2001).

Assim sendo, e começando pelos valores de stress e burnout, o principal aspeto a reter é o aumento nessas duas dimensões entre os períodos avaliados. Mais concretamente, os níveis mais elevados de stress passaram a ser referidos por uma percentagem mais significativa de professores (de 38\% em 2004/2005, a percentagem aumentou para 50\% em 2008/2009), estando esse valor acima do encontrado em outros estudos realizados com professores portugueses (ver GOMES et al., 2006), embora também seja possivel identificar investigações que encontraram percentagens desse tipo (ver GOULART JÚNIOR; LIPP, 2008; PINTO; LIMA; SILVA, 2005). Tal aumento foi igualmente acompanhado pela subida nas percentagens da sindrome de burnout nas três dimensões avaliadas (e.g., a exaustão emocional sobe de $10 \%$ para $18 \%$; a despersonalização, de $0,4 \%$ para 2,3\%; e a baixa realização pessoal, de 2,8\% para 3,4\%).
Quando analisamos os fatores de stress que podem explicar esses dados, confrontamo-nos com alguns aspetos curiosos. Desde logo, os comportamentos inadequados e a indisciplina dos alunos mantém-se como sendo a principal dimensão de pressão para os professores, confirmando, assim, dados de outros estudos, que sistematicamente referem esse âmbito como um dos mais perturbadores do funcionamento desses profissionais (ver DANIELS; BRADLEY; HAYS, 2007; EVERS; TOMIC; BROUWERS, 2004; ROYER, 2003; STEEL, 2001). Porém, enquanto em 2004/2005 eram as políticas disciplinares inadequadas o segundo fator de stress, em 2008/2009 assistimos a um aumento significativo da pressão associada ao trabalho burocrático e administrativo, podendo questionar-se a eventual relação desse aspeto com as alterações do Estatuto da Carreira Docente, que passou a implicar procedimentos burocráticos distintos dos anteriores. Aliás, as pressões de tempo e excesso de trabalho e o stress associado à carreira docente sobem na hierarquia de fatores de stress dos professores em 2008/2009, e baixam, nesse mesmo ranking, tanto o stress associado às políticas disciplinares inadequadas, quanto, principalmente, o stress relacionado com as diferentes capacidades e motivações dos alunos, que passou para sexto e último lugar. Assim sendo, e retirando a faceta relacionada a comportamentos inadequados e indisciplina dos alunos, em 2008/2009, os professores parecem mais pressionados por atividades não diretamente associadas à docência, por exemplo, a realização de tarefas de natureza burocrática e administrativa e as pressões de tempo e excesso de trabalho. Esses domínios de pressão laboral têm vindo a ser referidos na literatura e há indicações sobre seu impacto no bem-estar dos professores, podendo também contribuir para a síndrome de burnout (ver BYRNE, 1999; CHAN; HUI, 1995).

Tal padrão de resultados é substancialmente confirmado pelas análises comparativas realizadas. $\mathrm{Na}$ realidade, assistimos a um au- 
mento significativo da experiência de stress global entre 2004/2005 e 2008/2009, bem como a uma maior pressão associada a comportamentos inadequados e indisciplina dos alunos, pressões de tempo e excesso de trabalho, e trabalho burocrático e administrativo nos dois períodos. Entretanto, devemos realçar que as mudanças no stress relacionado com os comportamentos inadequados e de indisciplina dos alunos, bem como nas pressões de tempo e excesso de trabalho, obtiveram resultados significativos ou quase significativos consoante os testes aplicados (ver secção de Resultados). Seja como for, todas essas dimensões apontam para a ideia de que, num período de três anos, aumentou significativamente a experiência de stress dos professores. E o dado mais curioso, que eventualmente reforça a conclusão dos dados de frequência de stress, é o facto de a pressão associada às diferentes capacidades e motivações dos alunos diminuir de modo signifıcativo nas duas fases de avaliação. Ou seja, os professores parecem mais pressionados por aspetos não diretamente relacionados com o ensino em sala de aula, como as tarefas de natureza administrativa e burocrática.

A esse padrão de resultados relativos ao stress correspondem também aumentos significativos no sentimento de burnout, principalmente no que se refere à exaustão emocional. $\mathrm{Ou}$ seja, apesar de podermos afirmar que os níveis de burnout aumentam nas três facetas do instrumento aplicado nos períodos de avaliação, se retirarmos da amostra os professores da Região Autónoma dos Açores, tais variações demonstram ser evidentes apenas em relação à exaustão emocional. De um modo geral, esses resultados reforçam a ideia de que as exigências sobre os professores têm vindo a aumentar, de que é exemplo a necessidade de realizarem mais trabalho em menos tempo. Curiosamente, Woods (1999) alerta para a possibilidade de esses aumentos na carga de trabalho estarem a ocorrer sem que os professores possuam mais recursos para tal, e de que isso esteja também a acontecer num sistema de trabalho que oferece poucos reforços e reconhecimento. Se pensarmos que o novo Estatuto da Carreira Docente foi fortemente contestado pelos professores, podemos levantar a possibilidade de o aumento na carga de trabalho não ter subjacente uma percepção positiva de recompensa em termos de carreira profissional.

Por último, as análises de regressão. Dados os valores de variância explicada, a faceta de exaustão emocional é aquela que despertará maior interesse de análise. Nesse caso, podemos constatar que não existem variações nas variáveis preditoras nos dois avaliados (e.g., comportamentos inadequados e indisciplina dos alunos, pressões de tempo e excesso de trabalho, e diferentes capacidades e motivações dos alunos). Por outro lado, das restantes dimensões de burnout preditas, resulta também evidente que são os alunos (devido aos comportamentos incorretos ou à disparidade de capacidades) que melhor predizem a baixa realização pessoal e a despersonalização. Um dos dados mais interessantes prende-se com o facto de a carreira docente não se ter assumido como variável preditora em nenhuma das avaliações realizadas, sugerindo-se, assim, que são os aspetos mais relacionados com os próprios alunos que melhor predizem a experiência profissional dos professores.

Em síntese, os resultados deste estudo demonstram um aumento na experiência de stress e da síndrome de burnout dos professores. Alguns desses indicadores parecem sugerir que, para além dos problemas de comportamento dos alunos (principal fonte de stress em ambos os momentos de avaliação), os professores, em 2008/2009, aumentaram significativamente o stress ocupacional devido às pressões de tempo e excesso de trabalho, bem como devido ao trabalho burocrático e administrativo. Dada a natureza transversal deste estudo, bem como o facto de o stress associado à carreira docente não ter sofrido oscilações entre os dois momentos de avaliação, não podemos concluir por uma relação 
com as alterações legais introduzidas recentemente em Portugal no Estatuto da Carreira Docente. Seja como for, não devemos desprezar o facto de algumas dimensões de stress aparentemente relacionadas com essa mudança do Estatuto terem sofrido aumentos significativos entre 2004/2005 e 2008/2009 (e.g., pressões de tempo e excesso de trabalho, e trabalho burocrático e administrativo), cabendo à investigação futura clarificar melhor essa questão em novas avaliações desses temas junto da classe docente.

\section{Referências}

ARONSSON, Gunnar; SVENSSON, Lennart; GUSTAFSSON, Klas. Unwinding, recuperation, and health among compulsory school and high school teachers in Sweden. International Journal of Stress Management, v. 10, p. 217-234, 2003.

BRACKETT, Marc A. et al. Emotion-regulation ability, burnout, and job satisfaction among British secondary-school teachers. Psychology in the Schools, v. 47, n. 4, p. 406-417, 2010.

BROTHERIDGE, Celeste M.; GRANDEY, Alicia A. Emotional labour and burnout: Comparing two perspectives of "people work". Journal of Vocational Behavior, v. 60, p. 17-39, 2002.

BURKE, Ronald J.; GREENGLASS, Esther R. Towards an understanding of work satisfaction and emotional well-being of schoolbased educators. Stress Medicine, v. 10, p. 177-184, 1994.

BURKE, Ronald J.; GREENGLASS, Esther R.; SCHWARZER, Ralf. Predicting teacher burnout over time: effects of work stress, social support, and self-doubts and its consequences. Anxiety, Stress and Coping, v. 9, p. 261-275, 1996.

BYRNE, Barbara M. The nomological network of teacher burnout: a literature review and empirically validated model. In: VANDENBERGHE, Roland; HUBERMAN, A. Michael (Eds.). Understanding and preventing teacher burnout: a sourcebook of international research and practice. Cambridge: Cambridge University Press, 1999. p. 15-37.

CARLOTTO, Mary Sandra. A síndrome de burnout e o trabalho docente. Psicologia em Estudo, Maringá, v. 7, n. 1, p. 21-29, 2002.

CARLSON, Betty Clark; THOMPSON, John A. Job burnout and job leaving in public school teachers: implications for stress management. International Journal of Stress Management, v. 2, p. 15-29, 1995.

CHAN, David W. Stress, coping strategies and psychological distress among secondary school teachers in Hong Kong. American Educational Research Journal, v. 35, p. 145-163, 1998.

CHAN, David W.; HUI, Eadaoin K. P. Burnout and coping among Chinese secondary school teachers in Hong Kong. British Journal of Educational Psychology, v. 65, p. 15-25, 1995.

DANIELS, Jeffrey A.; BRADLEY, Mary C.; HAYS, Mary. The impact of school violence on school personnel: Implications for psychologists. Professional Psychology: Research and Practice, v. 38, n. 6, p. 652-659, 2007.

DINHAM, Stephen. Teachers under stress. Australian Educational Researcher, v. 20, n. 3, p. 1-16, 1993.

DUNHAM, Jack (Ed.). Stress in the workplace: past, present, and future. Philadelphia, PA: Whurr Publishers, 1992.

EVERS, Will J.G.; TOMIC, Welco; BROUWERS, André. Burnout among teachers: Students' and teachers perceptions compared. School Psychology International, v. 25, p. 131-148, 2004.

FIFE-SCHAW, Chris. Levels of measurement. In: BREAKWELL, Glynis Marie; HAMMOND, Sean; FIFE-SCHAW, Chris (Eds.). Research methods in psychology. 3. ed. London: Sage, 2006. p. 50-63. 
GOMES, A. Rui et al. Stress ocupacional no ensino: um estudo com professores dos $3^{\circ}$ ciclo e ensino secundário. Psicologia \& Sociedade, Campinas, v. 22, n. 3, p. 587-597, 2010.

GOMES, A. Rui et al. Problemas e desafios no exercício da actividade docente: Um estudo sobre o stresse, "burnout", saúde física e satisfação profissional em professores do $3^{\circ}$ ciclo e ensino secundário. Revista Portuguesa de Educação, Braga, v. 19, p. 67-93, 2006.

GOULART JÚNIOR, Edward; LIPP, Marilda E. Novaes. Estresse entre professoras do ensino fundamental de escolas públicas estaduais. Psicologia em Estudo, Maringá, v. 13, n. 4, p. 847-857, 2008.

GREENGLASS, Esther; FIKSENBAUM, Lisa; BURKE, Ronald J. Components of social support, buffering effects and burnout: Implications for psychological functioning. Anxiety, Stress and Coping, v. 9, p. 185-197, 1996.

HOWARD, Sue; JOHNSON, Bruce. Resilient teachers: resisting stress and burnout. Social Psychology of Education, v. 7, p. 399-420, 2004.

JOHNSON, Sheena et al. The experience of work-related stress across occupations. Journal of Managerial Psychology, v. 20, p. 179-187, 2005.

KYRIACOU, Chris. Teacher stress: directions for future research. Educational Review, v. 53, p. 27-35, 2001.

KYRIACOU, Chris; PRATT, J. Teacher stress and psychoneurotic symptoms. British Journal of Educational Psychology, v. 55, p. 61-64, 1985.

LIMA, Rosa Pedroso. 100 mil professores na rua. Expresso, edição on-line, 8 mar 2008. Disponível em: <http://aeiou.expresso. pt/100-mil-professores-na-rua=f262140>.

LITT, Mark D.; TURK, Dennis C. Sources of stress and dissatisfaction in experienced high school teachers. Journal of Educational Research, v. 78, p. 178-185, 1985.

MASLACH, Christina; JACKSON, Susan E.; LEITER, Michael P. (Eds.). Maslach Burnout Inventory Manual. 3. ed. Mountain View, CA: CPP, Inc, 1996.

MASLACH, Christina; JACKSON, Susan E.; SCHWAB, Richard L. Maslach Burnout Inventory - Educators Survey (MBI-ES). In: MASLACH, Christina; JACKSON, Susan E.; LEITER, Michael P. (Eds.). Maslach Burnout Inventory Manual. 3. ed. Mountain View, CA: CPP, Inc, 1996. p. 27-32.

MASLACH, Christina; SCHAUFELI, Wilmar B.; LEITER, Michael P. Job burnout. Annual Review of Psychology, v. 52, p. 397-422, 2001.

MOLEIR0, Raquel. Professores unidos nunca mais. Expresso, p. 16, 20 ago. 2011.

PIERCE, C. M. B.; MOLLOY, G. N. Psychological and biographical differences between secondary school teachers experiencing high and low levels of burnout. British Journal of Education, v. 60, p. 37-51, 1990.

PINTO, Alexandra Marques; LIMA, Maria Luisa; SILVA, Adelina Lopes da. Fuentes de estrés, burnout y estrategias de coping en profesores portugueses. Revista de Psicologia del Trabajo y de las Organizaciones, v. 21, p. 125-143, 2005.

PITHERS, R. T. Teacher stress research: problems and progress. British Journal of Educational Psychology, v. 65, p. 387-392, 1995.

PITHERS, R. T; SODEN, Rebecca. Person-environment fit and teacher stress. Educational Research, -

PORTUGAL. Decreto-Lei n 15 , de 19 de janeiro de 2007. Estatuto da carreira dos educadores de infância e dos professores dos ensinos básico e secundário. Diário da República Portuguesa, Lisboa, $1^{a}$ série, n. 14, jan. 2007.

Decreto-Lei $n^{\circ}$ 270, de 30 de setembro de 2009. Estatuto da carreira dos educadores de infância e dos professores dos ensinos básico e secundário. Diário da República Portuguesa, Lisboa, $1^{\text {a }}$ série, n. 190, set. 2009. 
Decreto-Lei n 75, de 23 de junho de 2010. Alterações no Estatuto da Carreira Docente e na Avaliação do Desempenho. Diário da República Portuguesa, Lisboa, $1^{a}$ série, n. 120, jun. 2010.

ROYER, Égide. What Galileo knew: school violence, research, effective practices and teacher training. Journal of Educational Administration, v. 41, p. 640-649, 2003.

SANN, Uli. Job conditions and wellness of German secondary school teachers. Psychology and Health, v. 18, p. 489-500, 2003.

SHIROM, Arie. Burnout in work organizations. In: COOPER, Cary L.; ROBERTSON, Ivan (Eds.). International review of industrial and organizational psychology. New York: Wiley, 1989. p. 25-48.

STEEL, Lindsay. Staff support through supervision. Emotional and Behavioural Difficulties, v. 6, p. 91-101, 2001.

TURK, D. C.; MEEKS, S.; TURK, L. M. Factors contributing to teacher stress. Implications for research, prevention, and remediation. Behavioral Counseling Quarterly, v. 2, p. 1-26, 1982.

VANDENBERGHE, Roland; HUBERMAN, A. Michael (Eds.). Understanding and preventing teacher burnout: a sourcebook of international research and practice. Cambridge: Cambridge University Press, 1999.

WESTMAN, Mina. Stress and strain crossover. Human Relations, v. 54, p. 717-752, 2001.

WOODS, Peters. Intensification and stress in teaching. In: VANDENBERGHE, Roland; HUBERMAN, A. Michael (Eds.). Understanding and preventing teacher burnout: a sourcebook of international research and practice. Cambridge: Cambridge University Press, 1999. p. 115-138.

Recebido em: 28.05.2011

Aprovado em: 22.09.2011

A. Rui Gomes é professor auxiliar da Escola de Psicologia da Universidade do Minho.

Ana Peixoto é psicóloga da Escola Secundária de Caldas das Taipas. E-mail: anampeixoto@iol.pt.

Rute Pacheco é aluna da Escola de Ciências da Saúde da Universidade do Minho. E-mail: rutealves@hotmail.com.

Maria Silva é aluna da Escola de Psicologia da Universidade do Minho. E-mail: msilva76@live.com.pt. 